\title{
A Ditadura Varguista no Brasil (1937-1945) e o Primer Franquismo na Espanha (1939-1945): poder e contra-poder das enfermeiras
}

\author{
The Vargas Dictatorship in Brazil (1937-1945) and the Primer Franquismo in Spain (1939-1945): \\ power and counter-power of nurses \\ La Dictadura Varguista en Brasil (1937-1945) y el Primer Franquismo en España (1939-1945): \\ poder y contra poder de las enfermeras
}

\section{Tânia Cristina Franco Santos', Maria da Luz Barbosa Gomes', Alexandre Barbosa de Oliveira', Antonio José de Almeida Filho'}

' Universidade Federal do Rio de Janeiro, Escola de Enfermagem Anna Nery. Rio de Janeiro-RJ, Brasil.

\author{
Submissão: 04-05-2011 Aprovação: 23-04-2012
}

\section{RESUMO}

Estudo histórico-social cujos objetivos foram os de descrever as principais características das ditaduras de Vargas e Franco e analisar as implicações destas para a institucionalização da enfermagem no Brasil e na Espanha. As fontes utilizadas foram documentos escritos localizados em arquivos brasileiros e espanhóis e a literatura relativa ao tema. A análise dos dados, apoiada por conceitos da Teoria do Mundo Social de Pierre Bourdieu, evidenciou que, no Brasil e na Espanha, no que se referia à divisão social do trabalho, o ponto de encontro entre Igreja e Estado consistia na reclusão da mulher no espaço privado. Conclui-se que as qualidades femininas foram capitalizadas pelas enfermeiras para legitimarem sua atuação no espaço público, ainda que para reproduzir neste espaço, consentido pelo Estado e pela Igreja, ocupações adequadas à feminilidade.

Descritores: Enfermagem; História da enfermagem; Brasil; Espanha.

\section{ABSTRACT}

This is a historical and social study, which aimed to describe the main characteristics of the Vargas and Franco dictatorships, and to analyze the implications of these to the institutionalization of nursing in Brazil and Spain. As fonts, it was used written documents located in the historical Brazilian and Spanish archives, in addition to the literature on the subject. Data analysis, supported by concepts of Pierre Bourdieu's World Social Theory, showed that, in Brazil and Spain, in referring to the social division of labor, the meeting point between Church and the State was the seclusion of women in private space. It is concluded that the feminine qualities were capitalized by the nurses to legitimize their actions in public space, even to reproduce in that space, consented to by the State and Church, occupations appropriate to femininity

Key words: Nursing; History of Nursing; Brazil; Spain.

\section{RESUMEN}

Estudio histórico y social que tuvo como objetivos describir las principales características de las dictaduras de Vargas y de Franco, y analizar sus implicaciones para la institucionalización de la enfermería en Brasil y en España. Fueran usadas como fuentes documentos escritos localizados en archivos históricos brasileños y españoles, además de la literatura relativa al tema. El análisis de los datos, apoyada por los conceptos de la Teoría del Mundo Social de Pierre Bourdieu, evidenció que, en Brasil y en España, en el que se refería a la división social del trabajo, el punto de encuentro entre Iglesia y Estado consistía en la reclusión de la mujer en el espacio privado. Concluye-se que las cualidades femeninas fueron capitalizadas por las enfermeras para legitimaren su actuación en el espacio público, aún que para reproducir en ese espacio, consentido por el Estado y por la Iglesia, ocupaciones adecuadas a la feminidad.

Palabras clave: Enfermería; Historia de la Enfermería; Brasil; España. 


\section{INTRODUÇÃO}

No Brasil, a ditadura do Estado Novo (1937-1945), instaurada por um golpe de Estado que garantiu a continuidade de Getúlio Vargas à frente do governo central, e na Espanha, a do Nuevo Estado (1939-1975) por Francisco Franco, que se deu em conseqüência da Guerra Civil Espanhola (1936-1939) em que Franco fora vitorioso, caracterizaram-se pela implantação de governos autoritários, com significativas repercussões sobre as instituições, os costumes e as relações de gênero(1).

No contexto político-social destes dois países, a diferença biológica entre os sexos, fundamento da ordem social, baseada principalmente na natureza anti-intelectual feminina, funcionava como um dos múltiplos argumentos que sustentavam a exclusão das mulheres de espaços públicos tradicionalmente consagrados aos homens, proclamando tanto a interdição de tarefas mais nobres como sua reclusão no lar.

Na Espanha, com o término da Guerra Civil em $1^{\circ}$ de abril de 1939, iniciou-se o período conhecido como Primer Franquismo (1939-1945), que se caracterizou como um período de intensa repressão aos focos de resistência armada contra o Nuevo Estado. Neste período, duas instituições se apresentavam significativamente reforçadas: as Forças Armadas, com um notável protagonismo político, mediante importante presença em todas as esferas da vida pública espanhola; e a Igreja Católica, suporte ideológico da nova sociedade em sua conformação mais conservadora ${ }^{(2)}$.

No Brasil, a aliança de Getúlio Vargas com a Igreja Católica começou antes mesmo da implantação da ditadura. A Igreja Católica se consolidou como importante ponto de apoio de Vargas, através da regeneração da moralidade social, consolidando uma ética e uma estética que valorizava a família, a obediência ao Estado e o trabalho (símbolo de dignidade). $\mathrm{O}$ governo, por sua parte, adotava medidas importantes que interessavam à Igreja Católica, isto porque, em um Estado laicizado, desde a proclamação da República (1889), tais medidas permitiriam à Igreja aumentar sua base social. Na prática, esta aliança projetava a hegemonia nacional e contribuía para a manutenção da ordem social.

No Brasil e na Espanha, no que se referia às mulheres, o ponto de aproximação importante entre Igreja e Estado consistia na (re)orientação delas para o espaço privado, o lar cristão - microespaço que refletia as construções simbólicas, mais tradicionais, relativas às diferenças entre os sexos.

Não obstante, as qualidades femininas que simbolizam os fundamentos objetivos da diferença entre os sexos, no sentido de gêneros construídos como duas essências sociais hierarquizadas, foram capitalizadas pelas enfermeiras brasileiras e espanholas para se fazerem ver, se darem a conhecer e se fazerem reconhecer, ainda que para produzir no espaço público, consentido pelo Estado e pela Igreja, serviços e ocupações adequadas à feminilidade.

Assim, o presente estudo se justifica porque representa uma contribuição ao avanço do conhecimento científico no que concerne ao aprofundamento da discussão sobre a divisão material e simbólica de espaços e práticas sociais implícitas na divisão social do trabalho que legitima a visão androcêntrica, mediante a evocação de atributos femininos no exercício da profissão de enfermeira, os quais demarcam a persistência da repartição dos papéis sexuais no seu cotidiano, através do cuidado discreto, carinhoso e abnegado ${ }^{(3)}$.

Diante da problemática apresentada foram elaborados os seguintes objetivos: descrever as principais características das ditaduras de Getúlio Vargas e de Francisco Franco e analisar as implicações destas ditaduras para a institucionalização da enfermagem nesses dois países.

\section{MÉTODO}

Trata-se de um estudo histórico-social, de abordagem qualitativa, cujas fontes primárias foram constituídas de documentos escritos localizados em arquivos brasileiros e espanhóis: Centro de Documentação da Escola de Enfermagem Anna Nery / Universidade Federal do Rio de Janeiro, Biblioteca Nacional, Biblioteca Pública de Valladolid, Archivo Municipal de Valladolid e Biblioteca Pública de Madrid. Os dados foram coletados no período de 21 de janeiro de 2009 a 30 de outubro de 2010. O presente estudo foi aprovado pelo Comitê de Ética em Pesquisa da Escola de Enfermagem Anna Nery / Hospital São Francisco de Assis em 26 de março de 2009 sob o número de protocolo 04/2009.

O estudo comportou as etapas essenciais preconizadas pelo método histórico. Assim, após a seleção e classificação das fontes primárias, procedeu-se: a crítica externa, mediante o exame de sua autenticidade com base na autoria, procedência e natureza dos documentos; e a crítica interna teve como finalidade a apreensão do conteúdo, significado e veracidade dos documentos ${ }^{(4)}$. Este processo permitiu a validação das fontes históricas que foram selecionadas para o estudo. Cabe ainda a menção de que as fontes secundárias, constituídas de artigos e livros, consubstanciaram a análise dos dados derivados das fontes primárias eleitas, as quais constituíram o corpus documental.

A análise dos dados foi respaldada por referências literárias selecionadas, com destaque para as que tratam da Teoria do Mundo Social do sociólogo francês Pierre Bourdieu, especialmente no que concerne aos conceitos de habitus e de poder simbólico. O argumento central de Bourdieu é o de que as práticas sociais são estruturadas, isto é, apresentam propriedades típicas da posição social de quem as produz, expressadas através do habitus, o qual "traduz as características intrínsecas e relacionais de uma posição em um estilo de vida unívoco, ou seja, em um conjunto unívoco de escolhas, de bens e de práticas" ${ }^{\prime(5)}$. Sendo assim, o habitus simboliza os indivíduos nos espaços sociais, porque se expressa através de práticas distintas e distintivas. Já o conceito de poder simbólico, também aplicado ao estudo, contribuiu para a análise da profissionalização da mulher e da enfermeira, no contexto de ditaduras que enunciavam e homologavam bases severas de inflexíveis divisões de gênero. Neste aspecto, o estudo agregou valor ao conhecimento científico já publicado, quando evidencia os estreitamentos entre os estudos sobre a história das mulheres e das enfermeiras, e quando traz a lume as imbricações entre questões de gênero e de relações de poder e de dominação. 


\section{MULHERES NAS DITADURAS: FORMAÇÃO PARA O "DOCE LAR" OU REPRODUÇÃO DO “DOCE LAR" NO ESPAÇO PÚBLICO}

\section{O caso da Espanha}

Pio XII (1876-1958), autoridade máxima da Igreja Católica, eleito Papa em 2 de março de 1939, legitimou explicitamente o comando de Francisco Franco na recristianização da Espanha ao afirmar que: en su política de pacificación todos sigan los principios inculcados por la Iglesia y proclamados con tanta nobleza por el generalísimo: de justicia para el crimen y de benévola generosidad para los equivocados( ${ }^{(6)}$. Com efeito, a eficácia do discurso performativo e consagrador de Pio XII, proporcional à autoridade de seu enunciador, contribuía para a manutenção da nova ordem política comandada por Franco, uma vez que seu discurso operou como signo de autoridade a ser acreditado e obedecido.

A aliança entre a Igreja e o Estado também se expressa na assimilação da Guerra Civil Espanhola como uma cruzada, o que foi enunciado no mesmo discurso de Pio XII: reconocemos también nuestro deber de gratitud hacia todos aquellos que han sabido sacrificarse hasta el heroísmo en defensa de los derechos invulnerables de Dios y de la religión en los campos de batalla ${ }^{(6)}$.

Ademais, Pio XII, ao consagrar a Espanha como baluarte inexpugnável da fé católica, homologava simbolicamente o poder de Franco, o que tornava impossível qualquer debate ideológico: los designios de la Providencia, amadísimos hijos, se han vuelto a manifestar, una vez más sobre la heroica España, la nación elegida por Dios como principal instrumento de evangelización del mundo(6).

Por sua vez, Franco reconheceu a importância do apoio da Igreja Católica ao seu regime e impôs o catolicismo como norma de vida. Com isso, os espanhóis se viram imersos, por gosto ou por força, na transcendente tarefa de avançar até Deus. Nesse sentido, o cidadão deveria esforçar-se para parecer metade monge, metade soldado, à imagem e semelhança de um regime que também se apoiava no Exército(7).

No caso específico das mulheres, exerceu-se um poder repressivo contra as mesmas através de legislações e práticas simbólicas que consagravam a submissão das espanholas aos seus familiares homens: pais, irmãos e maridos. Não obstante, o reconhecimento da importância da mulher na reprodução biológica e social, em face de suas qualidades como ternura, doçura, amor, compreensão, virtude moral, entre outras, tornavam-nas necessárias como educadoras ou cuidadoras de sua própria família ou como enfermeiras no espaço público, portanto, indispensáveis ao bem estar coletivo que era atribuído às mulheres em situação de guerra e de paz por meio de feitos considerados como uma extensão das naturais funções maternas e domésticas, contribuindo para ratificar a importância das qualidades intrínsecas à natureza feminina. ${ }^{(8,9)}$.

Por ocasião da Guerra Civil Espanhola, muitas mulheres, motivadas pelo sentimento patriótico e humanitário, apresentaram-se como voluntárias, embora com formação educacional bastante incompleta. Para paliar a sentida falta de capacitação profissional foram realizados cursos de curta duração como: Enfermeras de la Cruz Roja, Cuerpo Auxiliar de Damas Enfermeras Militares, Enfermeras de Guerra, Enfermeras del Socorro Rojo, Damas Enfermeras Españolas etc ${ }^{(10)}$.

Vale ressaltar que a Sección Femenina de la Falange Española Tradicionalista y de las JONS, que fora fundada em 1934, desenvolveu-se significativamente durante a Guerra Civil. O estatuto de 1937 já estabelecia que sua tarefa era a de desenvolver um modelo de mulher como complemento ao do homem, porém, sem nenhuma reciprocidade ${ }^{(10)}$.

Após a Guerra Civil, a primeira aparição pública da Sección Femenina de la Falange Española Tradicionalista y de las JONS dirigida por Pilar Primo de Rivera, irmã do José Antonio de Rivera - fundador da Falange - ocorreu em maio de 1939, no âmbito das comemorações da vitória. Na ocasião, Franco, ao tempo em que relembrou com frases impregnadas de retórica patriótica e religiosa o papel desenvolvido pela organização durante a guerra, também indicou a reconquista do lar como tarefa nacional das falangistas. Para dar conta, a Sección Femenina atuou em todo território nacional através das Hermandades para la Ciudad y el Campo, do Servicio Social, das Escuelas del Hogar nos bairros e prisões, promovendo atividades assistenciais e de formação e modelação do comportamento da mulher, mediante o controle de seu corpo e de suas atitudes ${ }^{(2)}$.

Pilar Primo de Rivera, autoridade máxima e vitalícia da Sección Femenina internalizou perfeitamente essa submissão, encarnada como uma submissão a Franco, uma vez que, ao longo da ditadura de Franco, Pilar manteve um discurso que reafirmava a inferioridade da mulher em relação ao homem. Tanto assim que a revista Medina dirigida às mulheres e editada pela Sección Femenina chegou a publicar em 13 de agosto de 1944: La vida de toda mujer, a pesar de cuanto ella quiera simular - o disimular - no es más que un eterno deseo de encontrar a quien someterse...(11)

Este discurso permaneceu inalterado durante as décadas seguintes, buscando inculcar na mulher espanhola seu caráter de inferioridade, porém, destacando a dignidade e a importância do trabalho no âmbito do lar: una mujer que tenga a las faenas domésticas com toda regularidad, tiene ocasión de hacer tanta gimnasia como no hará nunca, verdaderamente, si trabajase fuera de casa. (...) si se piensa en los movimientos que son necesarios para quitar el polvo de los sitios altos, limpiar los cristales, sacudir los trajes, se darán cuenta que se realizan tantos movimientos de cultura física que, aun cuando no tienen como finalidad la estética del cuerpo, son igualmente eficacísimos precisamente para este fin $^{(10)}$.

Tal publicação é exemplar no sentido de evidenciar que a vocação doméstica imposta às mulheres espanholas era sublimada pela valorização das qualidades e funções femininas no processo de reconstrução de um Nuevo Estado necessariamente católico, nacional e fascista.

\section{O caso do Brasil}

No comando do Estado Novo, o poder pessoal de Getúlio Dornelles Vargas representava a instância decisiva nas resoluções políticas. Nesse contexto, as Forças Armadas, base de sustentação do Estado Novo, atingiram a culminância de 
sua influência, derrotando os adversários do governo e eliminando sua capacidade de reação pelo fechamento dos mecanismos de participação. Com efeito, os militares foram enquadrados como atores sociais importantes no projeto de desenvolvimento nacional liderado por Vargas ${ }^{(12)}$.

O poder pessoal de Vargas também se consolidou mediante estratégias que visavam à personificação do mito. Eram organizados desfiles, manifestações e programas de rádio com vistas a enaltecer suas qualidades pessoais e garantir a disseminação social de uma imagem favorável do ditador através de dispositivos simbólicos de manipulação e coação, que contribuíam para que o povo reconhecesse o presidente como um porta-voz autorizado para falar e agir em nome deste povo $^{(13)}$.

O controle dos meios de informação através do Departamento de Imprensa e Propaganda, criado em 1939, fruto da ampliação da capacidade de intervenção do Estado no âmbito dos meios de comunicação e cultura, estimulava o culto ao Estado e disseminava rituais coletivos que exaltavam sempre a figura de Vargas. Portanto, graças a esse monopólio dos meios de comunicação, o Estado pôde manipular e exercer um controle rigoroso servível para a legitimação do novo poder, oriundo de um golpe ${ }^{(14)}$.

No que tange à condição da mulher, a Lei Orgânica do Ensino Secundário, também conhecida como Reforma Capanema, que permaneceria em vigor até a aprovação da Lei de Diretrizes e Bases da Educação Nacional de 1961, é exemplar por ter reproduzido e legitimado a divisão hierarquizante dos papéis sociais do homem e da mulher, pois os artigos destinados à educação feminina pontuavam as virtudes próprias da mulher, consagrando sua missão de esposa e de mãe e, sobretudo, seu papel de colaboradora do outro sexo na construção da Pátria. Em oposição, a educação masculina considerava atributos como a coragem, a força de vontade, a compreensão do dever - qualidades dos grandes homens da Nação, heróis da vida civil e militar ${ }^{(15)}$.

Esta mesma lei determinou que o ensino secundário das mulheres se efetivasse em classes exclusivamente femininas (Artigo 25, Item 1), o que dificultava a relação entre os sexos. A prescrição da disciplina "Economia Doméstica", indicada somente para as mulheres (Artigo 24, Item 3), ratificava a repartição dos papéis sexuais que reproduzia a dominação masculina, mediante "as condutas de marginalização impostas a elas através de sua exclusão de lugares públicos e, por conseguinte, de sua exclusão de tarefas mais nobres" (15).

Outrossim, as associações femininas católicas, tradicionalmente ligadas à educação e à assistência feminina, contribuíram de forma significativa para o ensino desse tipo de disciplina. Nesse sentido, logo após a promulgação da Lei Orgânica do Ensino Secundário, tem-se como manifestação emblemática a organização de um curso de emergência pela Liga de Senhoras Católica de São Paulo, para a preparação de professores de Economia Doméstica, sob os auspícios do Ministério da Educação e Saúde. Neste curso, as aulas de higiene tratavam do corpo, do vestuário, da escola e do lar. No tocante às aulas de enfermagem, elas comportavam conteúdos inerentes aos cuidados com os doentes relativos ao ambiente e visitas, além do aprendizado de alguns procedimentos tais como verificação de temperatura, pulso e aplicação de injeções. Eram ensinadas ainda receitas culinárias e noções de economia doméstica relativas à utilização consciente do salário do chefe da família. Também, os conteúdos inerentes à sociologia educacional demarcavam o papel da família, da Igreja e do Estado ${ }^{(15)}$.

Tais conteúdos refletem que a repartição de tarefas deveria ser iniciada no âmbito da vida familiar, onde o papel da muIher a ser perpetuado deveria ser de cuidadora e criadora ${ }^{(3)}$. Como constatado, algumas noções de enfermagem fizeram-se constar em programas secundários da disciplina Economia Doméstica, aonde era evocada a natureza da enfermagem como extensão de atividades tipicamente femininas, o que contribuía para reforçar os papéis sexuais no exercício da profissão, mediante a natureza de seu trabalho como extensão das atividades domésticas, e que, de um modo ou de outro, acabava por neutralizar possibilidades de se concorrer com os homens nos espaços públicos.

\section{DITADURAS: PODER DAS ENFERMEIRAS OU O PODER SOBRE AS ENFERMEIRAS}

Na ditadura de Vargas foi reproduzido um discurso que fragilizava os princípios democráticos tendentes a uma maior igualdade de gênero através de dispositivos materiais e simbólicos, que legitimavam uma relação de dominação baseada nas diferenças biológicas entre os sexos. Tanto assim que, Gustavo Capanema, Ministro da Educação de 1937 a 1945, em uma conferência realizada por ocasião do Centenário do Colégio Pedro II em dois de dezembro de 1937, pontuou a diferença entre os sexos como determinante das práticas sociais, ao afirmar que: (...) a educação a ser dada aos dois há, porém, de diferir na medida em que diferem os destinos que a Providência Ihes deu. Assim, se o homem deve ser preparado com têmpera de teor militar para os negócios e as lutas, a educação feminina terá outra finalidade que é a vida para o lar... ${ }^{(15)}$. Desse modo, o efeito simbólico das palavras de Capanema reside na possibilidade de institucionalizar propriedades de natureza social como se fossem de natureza natural, em face do reconhecimento de sua autoridade.

No que se refere à mulher espanhola, a conferência de Don Santos Begueristáin, promovida pela Asociación Católica de Padres de Família, em 1943, é emblemática no sentido de consagrar simbolicamente a assimetria de gênero ao destacar, no homem e na mulher, os signos exteriores mais imediatamente conformes à definição social de sua diferenciação sexual, mediante o estímulo de práticas convenientes a cada sexo: (...) afortunadamente en España está arraigada la idea del matrimonio no sentido cristiano. El hombre tiene sus hijos, su esposa, considera esencial la fidelidad, defiende como un tesoro inapreciable la virtud de sus hijos y el honor de sus hijas ${ }^{(16)}$.

Estas consagrações de ordem física e social colocavam o homem na condição de "senhor do privado e da família que eles governavam e representavam, delegando às mulheres a gestão do cotidiano" ${ }^{(8)}$, constituindo-as como subordinadas e submetidas, contribuindo para reforçar a hierarquia entre 
os sexos, proclamada como necessária à reordenação dos espaços sociais tanto na sociedade brasileira quanto na espanhola, no contexto das ditaduras de Vargas e de Franco, respectivamente.

Não obstante, as demandas de saúde do país, juntamente com o interesse do governo de Franco em modelar o comportamento das jovens, contribuíram para que a formação de enfermeiras adquirisse grande importância para a Sección Femenina, já que o modelo de mulher que o novo regime propagava se coadunava com o modelo de enfermeira caridosa / abnegada / submissa difundido pela Sección Femenina. Aliás, a preocupação do regime em assegurar o ensino católico, assim como a estrita dependência da mulher, em geral, em relação ao homem e das enfermeiras, em particular, aos médicos evidencia-se nos programas de estudo das enfermeiras e nos livros destinados à sua formação(11).

O excerto extraído do Manual de Enfermería, escrito por Usandizaga, médico e diretor da Escuela de Enfermeras de la Casa de Salud Valdecilla, publicado em 1934 ( $1^{\text {a }}$ edição) e vigente como livro obrigatório para a maioria das escolas de enfermagem da Espanha até a década de 1960, quando estava em sua $8^{\text {a }}$ edição, ainda evidenciava os limites de atuação da enfermeira e a estrita necessidade de obediência ao médico: (...) el cumplimiento exacto de las órdenes médicas, es lo que caracteriza a una buena enfermera. (...) la enfermera tiene unas funciones auxiliares bien determinadas; el intentarse salirse de ellas constituye una falta de moralidad y en muchas ocasiones un delito ${ }^{(17)}$.

Assim, a postura submissa que era imposta às mulheres se refletia na determinação dos deveres das enfermeiras, evidenciando a divisão sexual do trabalho pela primazia concedida universalmente aos homens, "senhor das mulheres", e em particular pelos médicos, "senhor das enfermeiras".

Vale ressaltar que as enfermeiras espanholas tiveram muita dificuldade para obterem reconhecimento profissional. A institucionalização do "título de enfermeira" registra-se em 1915, quando a profissão passou a ser classificada em: praticantes, matronas e enfermeiras; portanto, havia na Espanha uma razoável diversificação da enfermagem em categorias.

No âmbito da ditadura franquista, a primeira normatização que afeta às profissões sanitárias é a de $1^{\circ}$ de março de 1940, a qual dispõe sobre a equiparação entre o curso de matronas e de praticantes, no que concerne ao número de anos e aos exames do curso. Não obstante, como requisitos para o acesso ao curso de matronas, as candidatas deveriam apresentar comprovante de maior idade e autorização do marido, caso fossem casadas. Um ano depois, em 21 de maio de 1941, uma ordem do Ministerio de Educación Nacional estabeleceu normas para obtenção do título de enfermeira. Esta ordem, entre outras, estabelecia que os estudos de enfermeira deveriam ajustar-se aos programas aprovados pelas Faculdades de Medicina ou em centro reconhecidos por elas, devendo ser de dois anos de duração. Além disso, o exame para a obtenção do título se realizaria perante uma banca examinadora composta por três examinadores da Faculdade de Medicina, sendo que um dos examinadores poderia pertencer à instituição de origem da candidata(11). Dessa forma, evidencia-se uma significativa dependência do médico na formação da enfermeira espanhola àquela época.

Esse dado ganha mais expressividade quando se observa as funções das enfermeiras e das matronas, especificadas na Ley de Sanidad Nacional de 1945, a qual estabelecia as competências dos três grupos sanitários existentes (praticantes, matronas e enfermeiras). A lei determinava que as matronas e enfermeiras fossem profissões exclusivamente femininas. As matronas deveriam atender aos partos, auxiliar aos médicos na assistência às mulheres grávidas, e estar sob às ordens destes. No caso específico das enfermeiras, suas funções centravam-se em um forte caráter técnico e vocacional, obediente ao médico e com conotações exclusivamente femininas da profissão. Anos depois, o Real Decreto de 27 de junho de 1952 viria a estabelecer a unificação de todos os estudos de enfermagem (praticantes, matronas e enfermeiras) em um único programa e com uma única denominação, qual seja de ajudante técnico sanitário. Somente com o início da democracia e a incorporação à universidade, a Ordem Ministerial de $1^{\circ} \mathrm{de}$ junho de 1977 origina o processo de unificação, adotando-se o nome de enfermeira para todos os profissionais ${ }^{(11)}$.

No que se refere à enfermagem brasileira, na década de 1920, no Rio de Janeiro, então capital do Brasil, foi implantada a enfermagem moderna, mediante a criação da Escola de Enfermagem Anna Nery, sob a égide da saúde pública, no bojo de uma reforma sanitária liderada pelo cientista e sanitarista Carlos Chagas, então diretor do Departamento Nacional de Saúde Pública, criado em 1920.

Em 1931, a Escola Anna Nery obteve a condição de "Escola Oficial Padrão" através do Decreto n 20.109, de 15 de junho, para fins de criação e equiparação das demais escolas de enfermagem do país. Este decreto vigorou até 1949 quando tal responsabilidade foi transferida para o Ministério da Educação e Saúde, conforme a Lei n 775 , promulgada em seis de agosto.

Alguns meses antes da implantação da ditadura, mas na vigência do governo provisório de Vargas, tem-se a incorporação da primeira escola de enfermagem brasileira (Escola de Enfermagem Anna Nery) à universidade através da Lei $n^{\circ} 452$, de cinco de julho de 1937. Esta incorporação, que refletiu o reconhecimento da formação de enfermeiras no sistema universitário, conferiu prestígio à enfermagem na sociedade brasileira, uma vez que "o espaço habitado ou apropriado funciona como uma espécie de simbolização espontânea do espaço social"(18), pois sua apropriação depende do capital possuído (individual ou coletivo) que se constituí como signo visível de poder, porque o espaço social reproduz, por exclusão ou distinção, as posições que o constitui. Nesse sentido, há vantagens diferenciais em ocupar esta ou aquela posição num espaço hierarquizado ${ }^{(19,20)}$.

Dessa forma, no caso brasileiro, o incentivo às profissões femininas, em consonância com o processo de industrialização do país, favoreceu um expressivo desenvolvimento da enfermagem, primeira profissão eminentemente feminina do campo da saúde a ingressar no sistema universitário. Na Espanha, tal inserção só foi possível com a implantação da democracia. Portanto, comparando as trajetórias da profissão, no 
âmbito das ditaduras brasileiras e espanholas, evidencia-se, na sociedade espanhola, especialmente no período de 1939 a 1945, uma maior intervenção do Estado na vida das mulheres e, por conseguinte, na profissionalização da enfermeira.

\section{CONSIDERAÇÕES FINAIS}

A necessidade de enfermeiras, no Brasil e na Espanha, possibilitou o exercício em público de atividades femininas através do cuidado aos enfermos, principalmente em situações de calamidades e de guerras, e, sob regimes políticos autoritários, contribuindo para a visibilidade de um modelo de enfermeira respaldado em aspectos patrióticos e religiosos.

Nesse sentido, as repercussões das ditaduras de Vargas e de Franco no desenvolvimento da enfermagem se traduziram na exaltação da pátria e da religião como referências para a atuação da mulher e da enfermeira nos espaços públicos, no contexto de uma ordem social que reafirmava o caráter de inferioridade da mulher em relação ao homem, mas pondo em destaque a importância de suas qualidades morais.

O trabalho de reprodução das relações de poder entre homens e mulheres, no contexto das ditaduras de Franco e Vargas, foi garantido por duas instâncias principais: a Igreja e o Estado, que, objetivamente orquestradas, convergiam no sentido de empreenderem estratégias que naturalizavam essas reproduções, mediante a consagração de atributos femininos.

Vale destacar que o estudo sobre as repercussões das ditaduras instauradas por Vargas, no Brasil, e por Franco, na Espanha, no desenvolvimento da enfermagem, permitiu aprofundar o entendimento da conformação estrutural de cada realidade, em suas diferentes dimensões espaço-temporais, bem como o trabalho de reprodução das relações de poder que refletia as construções simbólicas mais tradicionais, relativas às diferenças entre os sexos.

\section{REFERÊNCIAS}

1. Marín JM, Molinero C, Ysás P. Historia política de España. Madrid: Istmo; 2001.

2. Gomes-Ferrer G, Cano G, Barrancos D, Lavrin A. Historia de las mujeres en España y América Latina: del siglo XX a los umbrales del XXI. Madrid: Ediciones Cátedra; 2006.

3. Santos TCF, Barreira IE. A mulher e a enfermeira na nova ordem social do Estado Novo. Texto \& Contexto Enferm 2008;17(3):587-93.

4. Padilha MICS, Borenstein MS. O método de pesquisa histórica na enfermagem. Texto \& Contexto Enferm 2005;14(4):575-84.

5. Bourdieu P. A distinção: crítica social do julgamento. Porto Alegre: Zouk; 2007.

6. Hernandez M. El mensaje de S.S Pio XII a la católica España. El Norte de Castilla (Sección Femenina). 1939;18; Secc. 1 (col. 1).

7. Galán JE. Los años del miedo. Barcelona: Planeta; 2008.

8. Perrot M. Mulheres públicas. São Paulo: UNESP; 1998.

9. Oliveira AB, Santos TCF, Barreira IA, Almeida Filho AJ. As enfermeiras da Força Expedicionária Brasileira e a divulgação de seu retorno ao lar. Rev Latinoam Enferm 2009; 17 (6):1050-6.

10. Sección Femenina de la falange Tradicionalista y de las JONS. Gimnasia. Rev Teresa 1961;22(2):10-6.

11. Magdalena STP. Historia de la enfermería. In: Carmen FF, Margarita GA, Magdalena STP, María DSP. Enfermería fundamental. Barcelona: Masson; 1995.

12. Carvalho JM. Vargas e os militares: aprendiz de feiticeiro. In: D’Araújo MC. As instituições brasileiras da Era Vargas. Rio de Janeiro: Fundação Getúlio Vargas; 1999. p.55-81.

13. Camargo A. Carisma e personalidade: da conciliação ao maquiavelismo. In: D'Araújo MC. As instituições brasileiras da Era Vargas. Rio de Janeiro: Fundação Getúlio Vargas; 1999. p.13-33.

14. Capelato MHR. Multidões em cena. Propaganda política no Varguismo e no Peronismo. São Paulo: Papirus; 2009.

15. Schwartzman S, Bomeny HMB, Costa VMR. Tempos de Capanema. São Paulo: Paz e Terra; Fundação Getúlio Vargas; 2000.

16. Begueristáin DS. La misión de la mujer española. El Norte de Castilla (Asociación Católica de Padres de Familia) 1943; 09; Secc. 1 (col. 2).

17. Usadizanga SM. Manual de la Enfermera. San Sebastián: Librería Internacional; 1934.

18. Bourdieu P. Efectos de lugar. In: Bourdieu P. La miseria del mundo. Madrid: Akal; 1999. p.119-124.

19. Santos TCF, Gomes MLB. Nexos entre pós-graduação e pesquisa em enfermagem no Brasil. Rev Bras Enferm 2007;60(16):91-5.

20. Fonte AS, Santos TCF. Revista Annaes de Enfermagem: publicações de enfermeiras sobre pediatria (1932-1941). Rev Bras Enferm 2009;62(1):157-61. 